\title{
PRODUCTION AND IDENTIFICATION OF ENGLISH WORD-FINAL NASAL CONSONANTS BY BRAZILIAN EFL LEARNERS
}

\author{
Denise Cristina Kluge \\ Barbara Oughton Baptista
}

Universidade Federal de Santa Catarina

\section{Abstract}

This preliminary study aims at investigating the production and perception of the English nasals /m/ and / $\mathrm{n}$ / in word-final position by a group of 10 intermediate Brazilian EFL learners. Production data was collected by means of a Sentence Reading Test considering preceding vowel as phonological context. Perception was assessed by means of an identification test contrasting native-like vs. nonnative-like pronunciation of the target nasal consonants. The results from production suggest that the lack of fully realized word-final nasals in Brazilian Portuguese influenced the Brazilian learners' production, as they frequently nasalized the preceding vowel and deleted the following nasal consonant. The results from the identification test revealed that it was easier for the participants to identify the native-like realization of English word-final nasals when it was presented in contrast to the nonnative-like realization.

Keywords: perception, production, nasal consonants. 


\section{Introduction}

Second language (L2) acquisition research has often been compared to native language (L1) acquisition. Research has shown that interlanguage (IL) phonology is influenced by many factors, such as age (Major, 1994), style (Major, 1994), developmental factors (Flege \& Davidian, 1984) and L1 interference (Flege, 1995). L1 interference accounts for many errors in L2 production, although it cannot truly predict errors or explain other errors that may not be due to either L1 or L2 (Flege \& Davidian, 1984). Other studies involve the influence of markedness (Eckman, 1977), phonological environment (Carlisle, 1994), and perceptual considerations (Flege, 1995), for instance.

The studies cited above and many others have helped those who work in the field of L2 phonetics and phonology and second language acquisition (SLA) in general to identify the sources of errors in L2 acquisition. However, there is still a lot to be discovered about L2 acquisition.

In this study the production and the identification of English nasal consonants $/ \mathrm{m} /$ and $/ \mathrm{n} /$ in word-final position by ten intermediate Brazilian students of English were investigated. Production was assessed by means of a Sentence Reading test and perception by means of an identification test, which investigated whether the participants could identify the presence or absence of the nasal consonants $/ \mathrm{m} /$ and $/ \mathrm{n} /$ in word-final position in native-like and nonnative-like pronunciation. Preceding phonological context was also examined in production.

In order to understand the difficulties Brazilian learners have with English word-final nasals, phonological differences between the languages have to be considered. According to Fujimura and Erickson (1997), typically, nasal consonants have a place distinction between $/ \mathrm{m} /$ and $/ \mathrm{n} /$, as in English. However, many languages, such as Brazilian Portuguese (BP), have no place distinction for nasal consonants in word-final position. 
As explained by O'Connor (1975), in English syllable-final position, the nasal consonants $/ \mathrm{m} /$ and $/ \mathrm{n} /$ are fully pronounced by lowering the soft palate and blocking the mouth as follows: for the bilabial $/ \mathrm{m} /$, the mouth is blocked by closing the lips; whereas for the alveolar $/ \mathrm{n} /$, the mouth is blocked by pressing the tip of the tongue against the alveolar ridge, and the sides of the tongue against the sides of the palate (p. 64). As claimed by the author, the pronunciation of neither of the sounds should cause much difficulty for most speakers. However, $\mathrm{O}^{\prime}$ Connor also states that speakers of some languages, such as Portuguese, may find the pronunciation of these nasals difficult in syllable-final position:

instead of making a firm closure with the lips or tongue tip so that all the breath goes through the nose, they may only lower the soft palate and not make a closure, so that some of the breath goes through the nose but the remainder goes through the mouth. When this happens, we have a nasalized vowel (p. 65).

In $\mathrm{BP}$, it is accepted by most authors, that: (1) phonetically, the nasal consonants $/ \mathrm{m} /$ and $/ \mathrm{n} /$ are not fully realized after a vowel in syllable-final position (e.g., lindo [.liâdU]-'beautiful') and sometimes not realized at all, especially in word-final position (e.g., fim [fik 'end'); and (2) the vowel receives nasalization from the following nasal consonant (Câmara Jr., 1971; Cristófaro Silva, 1999; Mateus \& d'Andrade, 2000). These are assumptions of the present study. In English, vowels followed by nasal consonants are also nasalized (Giegerich, 1992, p.125); however, the degree of nasalization in English is weaker than in BP and it is not a distinctive feature, as it is in BP (e.g., lá [:la]- 'there' vs. lã [:la) - 'wool').

Due to the difference in the pronunciation of the nasal consonants $/ \mathrm{m} /$ and $/ \mathrm{n} /$ in syllable-final position in English and BP, Brazilian EFL learners may have difficulty in the production and perception of the English nasals in syllable-final, and especially word-final position. 
As posited by Flege (1981), L2 sounds may be perceived in terms of those of the L1 by the learner, making this perception different from that of a native speaker. For instance, sounds that are distinct phonemes in an L2 might be merely allophones of the same phoneme in the native language. Flege claims that this may influence the production of L2 sounds by a native speaker of this L1 because of the identical mental representation that the speaker would have for the two sounds. Thus, it might be expected in this study that some participants would perceive English word-final nasals "through the grid" (Wode, 1978, cited in Flege, 1995) of the corresponding BP sounds and, thus, apply the usual BP process of nasalization of the vowel and deletion of the nasal consonant in production.

Flege (1995) also posits in his Speech Learning Model (SLM) that the perceived relationship between L1 and L2 categories plays an important role in accurately perceiving or producing L2 sounds. The model hypothesizes that L1 and L2 sounds are "related perceptually to one another at a position-sensitive allophonic level" and acquisition of L2 sounds depends on the perceived dissimilarity between L1 and L2 sounds (Flege, 1995, p. 239). Therefore, Brazilian learners of English would be expected to have perceptual difficulty identifying English / $\mathrm{m} /$ and / $\mathrm{n} /$ in word-final position as, in BP, these nasal consonants in word-final position are not distinctive due to vowel nasalization and deletion of the nasal consonant.

\section{Production of nasal consonants}

Regarding the production of the nasal consonants and their acoustic characteristics, some relevant variables which have been considered by researchers are stress (Fujimura, 1962; Krakow, 1995), syllable position (Kurowski \& Blumstein, 1987; Repp, 1986; Repp \& Svastikula, 1988), and vowel context (Kurowski \& Blumstein, 1984, 1987; Krakow, 1995). For the purpose of the present study, this section summarizes studies focused on syllable position, particularly syllable-final position, 
and vowel context with native speakers of English and Brazilian learners of English.

Kurowski and Blumstein (1987) carried out two experiments in order to determine whether the acoustic properties of place of articulation of nasals could be derived for English labial and alveolar nasal consonants and to determine whether they remain stable across vowel context, speakers, and syllable positions. In the first experiment, speech tokens were analyzed consisting of a nasal consonant $[\mathrm{m}]$ or $[\mathrm{n}]$ in syllable-initial position $(/ \mathrm{CV} /)$ followed by one of the vowels [i,e, $a$, o, u] (e.g., [mi], [ne], etc.). In the second experiment, the syllable types consisted of the same nasal consonants in syllable-medial position $(\mathrm{CCV})$, that is, preceded by / $\mathrm{s} /$ and followed by one of the same vowels (e.g., [sni], [sne], etc.). In the analysis of the data from both experiments, the procedures used in Kurowski and Blumstein (1984) were followed: the point of release or discontinuity between the nasal murmur and the transitions into the following vowel "was visually identified in the waveform as a break in the pattern of murmur pulses and the beginning of high-frequency components" (p. 1920), and this was corroborated by spectral analysis using linear predictive coding (LPC).

Using this method, the researchers were able to identify place of articulation in more than $89 \%$ of the tokens in Experiment 1 and in $84 \%$ of the tokens in Experiment 2. All misclassifications occurred in the context of front vowels in both experiments: for the labials in the environment of the front vowel [i] in Experiment 1 and for the labials in the environment of the front vowels [i] and [e] in Experiment 2. The results of both experiments demonstrated that spectral patterns for nasal consonants are similar in these two syllable positions - syllable-initial and syllable-medial. However, the researchers had difficulties when they tried to identify these spectral patterns for nasals in syllable-final position (VC) with the same method used in CV and CCV syllables. They claimed that this failure may be related to the difficulty of locating the point of closure of unreleased nasal consonants (1987, p. 1924). 
The difference between syllable-initial and syllable-final nasal articulation is explained by Krakow $(1995$, p. 90), with reference to Fujimura (1990), Hendersen (1984), and Schourup (1973):

the phonetic and phonological evidence suggests that patterns of velic lowering and nasal assimilation are affected by the position of a nasal consonant in a word and hence, possibly in a syllable. Word-final nasal consonants are produced with greater and earlier velic lowering than wordinitial nasal consonants, and correspondingly, nasal assimilation is more likely to affect vowels preceding wordfinal nasals than those preceding or following word-initial nasal.

As to stress and vowel context as variables in the cross-language investigation of nasalization, Schourup (1973, cited in Krakow, 1995, p. 102) reported a relation between stress and nasalization, that is, stressed vowels were more likely to become nasalized by assimilation than unstressed vowels. This relationship raised the question of whether velic movements for all vowels were similarly affected by stress. Therefore, Krakow (1995) conducted a study in order to address this question.

The data was collected from two native English-speaking participants producing sequences of words in which the velic positions for stressed and unstressed /i/ and / A/ following and preceding a nasal consonant could be compared. The results for the vowels preceding nasals in syllable-final position showed that there were intrinsic differences in velic height between the two vowels: lower positions for /A/ than for /i/. According to Krakow (1995, p. 105), the results supported Schourup's claim that the vowels most likely to be contextually nasalized are low, stressed and precede a final nasal consonant.

Now turning to the production of English nasal consonants in syllable-final position by Brazilian EFL learners, few studies have been carried out, to the best of our knowledge. One of the few studies which deals specifically with the production of English syllable-final nasals 
by Brazilian learners is one by Monahan (2001), who investigated the interlanguage English of BP speakers residing in the United States concerning processes such as regressive assimilation of nasality and nasal deletion in syllable-final position. Data from a sentence reading task showed consistent and heavy nasalization of vowels with, in most cases, little or no evidence of the nasal consonant surfacing. The author points out that although a syllable-final nasal consonant does regressively assimilate its nasality to the preceding vowel in English, as in $\mathrm{BP}$, the difference lies in the fact that in English the nasal consonant is articulated, whereas in $\mathrm{BP}$ the nasal consonant is deleted or reduced to a minimum. According to Monahan, the results show that native BP speakers transfer the process of regressive assimilation of nasality and nasal deletion in syllable-final position to their English interlanguage.

Another relevant study also considering the production of English syllable-final nasals by Brazilian learners was conducted by Baptista and Silva Filho (2006), who investigated the influence of markedness and syllable contact on the production of English final consonants in general, including nasals, by Brazilian learners. Regarding the nasal consonants, the results showed, in addition to the vowel nasalization found by Monahan (2001), paragoge, that is, the addition of the vowel [i] in words with the final vocalic grapheme " $\mathrm{e}$ ", as strategies used by the participants to produce the English nasals consonants in syllablefinal position.

In relation to the effect of vowel context in the production of syllable-final nasals, to the best of our knowledge, the only study in which the preceding vowel was investigated as phonological context for the production of the English syllable-final nasals $/ \mathrm{m} /$ and $/ \mathrm{n} /$ by Brazilians is one reported in Kluge (2004). In this study, production data was collected by means of a sentence reading task carried out by twenty pre-intermediate Brazilian students of English. A perceptual analysis of the data showed that, in addition to the lack of fully realized syllable-final nasals in English, as occurs in BP, the low vowels tended to be more nasalized, disfavoring the accurate production of the 
following nasal consonants. These results for non-native speakers are consistent with those of Krakow (1995) for native speakers of English.

\section{Perception of nasal consonants}

As stated by Kurowski and Blumstein (1995, p. 199), studies have shown that vowel context influences the perception of the place of articulation of nasal consonants.

Zee (1981, cited in Kurowski \& Blumstein, 1995, p. 199) investigated the effect of vowel quality on the perception of post-vocalic nasal consonants (labials, alveolars and velars) in white noise (i.e., noise within a wide range of random frequencies of uniform intensity, inserted to make the task more difficult) by native speakers of English. The results showed that labials were often incorrectly identified as alveolars after the front vowels [i] and [e], and velar nasals tended to be perceived as alveolars after the high front vowel [i].

Similarly, in Sharf and Ostreicher (1973, cited in Kurowski \& Blumstein, 1995, p. 199), listeners identified [m] significantly more often before [u] than before [i] in noise, while [n] was identified significantly more often before [i] than before [u]. As reported by Kurowski and Blumstein, there are other studies on nasals that have also found this vowel context effect for the bilabials in the environment of the high front vowel (Kurowski \& Blumstein, 1984; Repp, 1986, all cited in Kurowski \& Blumstein, 1995, p. 199). The authors point out that the same perceptual effects involving labials in the environment of [i] and $[i, e]$ have been found with other consonant classes such as the oral stop consonants, for instance (Blumstein \& Stevens, 1980; Kewley-Port, 1983, all cited in Kurowski \& Blumstein, 1995, p. 199).

One important issue raised by Ohde, Haley and Barnes (2006, p. 1968) is the fact that perceptual research on cues to place of articulation identification for nasal consonants has been based, primarily, on studies with the nasal consonant in syllable-initial position. The authors state that significantly less is known about variations in the perception of nasals in syllable-final position. However, there is evidence indicating 
that the perceptual identification of consonants is more accurate (Repp \& Svastikula, 1988; Redford \& Diehl, 1999, all cited in Ohde, Haley \& Barnes, 2006) and acoustic properties more robust (Ohala, 1990; Manuel, 1991; Wright, 2001, all cited in Ohde, Haley \& Barnes, 2006) in CV syllables than in VC syllables (p. 1968).

As regards perception of non-native nasal consonants, few studies have been carried out. Harnsberger $(2000,2001)$ carried out crosslanguage studies in which he investigated the perception (discrimination and/or identification) of non-native nasal consonants by native speakers of Malayalam, Marathi, Punjabi, Tamil, Oriya, Bengali, and American English. Results of the identification test (Harnsberger, 2000) showed that labeling and rating of non-native stimuli were conditioned by a degree of language-specific phonetic detail that corresponds to perceptually relevant cues to native language contrasts (p.764). A multidimensional scaling analysis of the similarity scores of the discrimination test (Harnsberger, 2001, p. 322) revealed substantial effects of linguistic experience on the organization of perceptual space that cannot be accounted for by abstract units such as phonemes or allophones. According to the author, the seven listener groups could be regrouped in terms of their arrangement of nasals in the perceptual space according to attributes that are quite independent of their phonemic or allophonic inventory, such as the overall dispersion of nasals, different patterns of clustering of nasals (interdental-alveolarretroflex-palatal-velar), and the similarity observed between the bilabial and retroflex nasals (p. 322).

Aoyama (2003) conducted a two-experiment study in which she investigated the perception of syllable-initial and syllable-final nasals in English by Korean and Japanese listeners. In both Korean and English, $/ \mathrm{m} /$ and $/ \mathrm{n} /$ contrast syllable-initially and $/ \mathrm{m} /, / \mathrm{n} /$ and $/ \mathrm{N} /$ contrast syllable-finally. In Japanese, however, $/ \mathrm{m} /$ and $/ \mathrm{n} /$ contrast syllableinitially, whereas nasals do not contrast in syllable-final position. In the first experiment, Aoyama found that the Japanese listeners had significant difficulty distinguishing the syllable-final velar nasal (/ $\mathrm{N})$ from the alveolar $(/ \mathrm{n} /)$, although they had no particular problems 
distinguishing the final bilabial nasal $/ \mathrm{m} /$ from either the velar $/ \mathrm{N} /$ or the alveolar $/ \mathrm{n} /$.

In the second experiment, Aoyama examined the perceived relation between English /m/, /n/ and /N/ and the Japanese categories in order to explain the difficulty of the Japanese listeners with the syllable-final / $\mathrm{n} /-/ \mathrm{N} /$ distinction. The experiment showed that syllable-final $/ \mathrm{m} /$ was assimilated to one Japanese category, while two or more categories were used to classify /n/ and /N/. Aoyama concludes that the results of these experiments show that "perceptual difficulties in an L2 cannot be predicted simply from the comparison of phoneme inventories between learners' L1 and L2, and suggest that the perceived relationship between L1 and L2 segments plays an important role in how L2 segments are perceived" (p. 263).

Preceding vowel context, cited above as important in L1 nasal consonant perception, has also been found to be important in the perception of English nasal consonants $/ \mathrm{m} /$ and $/ \mathrm{n} /$ in syllable final position by Brazilian learners. Kluge and colleagues (Kluge, 2004; Kluge et al., 2007) in their investigation of the perception of syllable-final nasals by twenty pre-intermediate Brazilian students of English, assessed perception through a Categorial Discrimination Test, modeled after Flege, Munro and Fox (1994), and an Identification Test. A group of three native speakers also took both perception tests as a reference for comparison. The results from the perception tests revealed that the preceding vowel seemed to influence the accurate perception of the target nasals $/ \mathrm{m} /$ and $/ \mathrm{n} /$ by both the Brazilian learners and the native speakers. Both groups seemed to have difficulty, although to different degrees, in either discriminating or identifying the target nasals in the context of high vowels, while low vowels seemed to favor accurate perception. These results were consistent with the results found and reviewed by Kurowski and Blumstein $(1987,1995)$.

The above review shows that, while the results so far appear to be consistent, there still have been few studies on the perception and production of nasal consonants in syllable-final position by Brazilian EFL learners. Thus, in order to contribute further to the understanding 
of the production and perception of the nasal consonants in word-final position by Brazilian EFL learners, the research questions and hypotheses of this study were the following: (1) What strategies do the Brazilian learners of this study use when they do not fully realize the final nasal consonant (nasalization of the preceding vowel and deletion of the nasal consonant or deletion of the nasal consonant without vowel nasalization)? It was hypothesized, based on previous studies, that the participants of this study would nasalize the preceding vowel and delete the nasal consonant (Baptista \& Silva Filho, 2006; Monahan, 2001; Kluge, 2004; Kluge et al., 2007). (2) How does the height of the preceding vowel (high, medium and low) influence the Brazilian EFL learners' production of English word-final nasals / $\mathrm{m} /$ and $/ \mathrm{n} /$ ? The hypothesis was that the preceding vowel would influence the production of English word-final nasals by these Brazilian EFL learners: preceding low vowels would be more prone to nasalization and disfavor the complete realization of the nasal consonant (Krakow, 1995; Kluge, 2004; Kluge et al. 2007). (3) Are the Brazilian learners able to perceive the distinction between native-like vs. nonnative-like realization of English wordfinal nasals and identify the native-like one by its full realization? The hypothesis for this question was that the Brazilian learners of this study would be able to perceive the distinction between native-like vs. nonnative-like realizations of English word-final nasals and identify the native-like one only when presented in contrast (Kluge, 2004).

\section{Method}

\subsection{Participants}

Ten participants were tested: seven women and three men, ranging in age from 18 to 25 . All participants were students from the Universidade Federal de Santa Catarina in Brazil, regularly attending either the third semester of the undergraduate English program or the fourth or fifth semester of the Extracurricular English Language course, all considered to be at the intermediate level, the latter course having fewer hours per semester. In order to ensure the level of the 
participants, fifteen students recorded a short free speech sample talking about themselves. The participants talked freely for one minute using an outline provided by the researchers. Two English speakers (a native speaker and one of the researchers, who is nonnative) rated the pronunciation of the participants holistically from nonnative-like to close to native-like on a scale 1 to 5,1 being nonnative-like and 5 close to native-like. The five participants who were rated 1 or 5 were excluded in order to avoid the two extremes of proficiency. Thus, the ten participants of this study were rated from 2 to 4 . According to the participants' report, everyone in the group resided in Florianópolis, Santa Catarina at the time of data collection. None of them had been to any English-speaking country and none had had extensive exposure to English outside the classroom setting. All the participants also reported greater exposure to American English than to British or any other variant. Six of the ten participants reported that they had never had formal instruction on English sounds and pronunciation and/or on phonetic symbols. All the participants also reported having no hearing problems.

\subsection{Instruments}

In order to test participants' production and perception of the English nasals $/ \mathrm{m} /$ and $/ \mathrm{n} /$ word-final position, a questionnaire to obtain the participants' biographical information (such as age, gender and regional accent, as well as information related to their English learning experience), and two tests were designed: (1) a sentence reading test, and (2) a native-like ( $\mathrm{N}$-like) vs. nonnative-like (NNlike) identification test.

\subsubsection{Sentence-reading test}

The production data-gathering instrument consisted of sentences specially designed to ensure the inclusion of the relevant phonological environment in the corpus. The sentences were checked for content and grammatical correctness by a native speaker of English. There were 72 sentences containing a monosyllabic (C)CVC target word in 
stressed position with one of the nasals $/ \mathrm{m} /$ or $/ \mathrm{n} /$ in word-final position: 36 containing $/ \mathrm{m} /$ and 36 with $/ \mathrm{n} /$. The sentences varied in length from five to eight words.

In order to investigate the influence of the preceding vowel on the production of the nasals in word-final position, the monosyllabic words contained high (/I/), mid (/E/) and low (/Q/) front vowels before the target nasal. Lax vowels were chosen in order to guarantee exclusion of words with the final grapheme " $\mathrm{e}$ ", which could have caused a spelling effect. As found in Baptista and Silva Filho (2006), nasals in word-final position followed by " $\mathrm{e}$ " may cause epenthesis, rather than vowel nasalization and nasal consonant deletion, when produced by Brazilian learners.

To control for following context, which was not considered in the analysis, each of the monosyllabic (C)CVC target words ending in either $/ \mathrm{m} /$ or $/ \mathrm{n} /$ occurred in one of the following twelve contexts: (a) a word beginning with one of the following stop consonants regarding place of articulation: a bilabial / $\mathrm{p}, \mathrm{b}, \mathrm{m} /$, an alveolar $/ \mathrm{t}, \mathrm{d}, \mathrm{n} /$ or a velar $/ \mathrm{k}, \mathrm{g} / ;$ (b) a word beginning with $/ \mathrm{l} /, / \Lambda /$, or $/ ə /$; or (c) silence, that is, at the end of the sentence. Thus, there were twenty-four sentences for each preceding vowel: twelve with the nasal $/ \mathrm{m} /$ and twelve with the nasal / $\mathrm{n} /$ in word-final position. The following sentence exemplifies the contextualization: "He is a very slim boy" contains a monosyllabic word with $/ \mathrm{m} /$ in word-final position, preceded by the high vowel /l/, and followed by the voiced bilabial stop /b/.

The sentences in the test were randomized for presentation so that each participant received a different order, thus minimizing possible ordering effects. The sentences were printed out on two sheets and the participants were asked to read the sentences at normal speed, which was controlled by the researchers. The participants were also asked to repeat a sentence any time the researchers considered that the sentence was read too fast or in an unclear manner. The participants were recorded in a quiet room at Universidade Federal de Santa Catarina with a Sony MZ-NHF800 minidisk recorder and a Sony ECM- 
MS907 directional microphone. The recordings were then digitized for analysis at a sampling frequency of $22.050 \mathrm{~Hz}$, which was considered sufficient to obtain consistent acoustic measurements of the target speech sound.

\subsubsection{Native-like vs. nonnative-like identification test}

The second data-gathering instrument consisted of an identification test format to check whether the participants could identify native-like versus nonnative-like pronunciation of the English word-final nasal consonants $/ \mathrm{m} /$ and $/ \mathrm{n} /$, distinguished by the presence or absence of the nasal consonants and the nasalized or oral pronunciation of the preceding vowels, which, contrary to a typical Brazilian pronunciation, maintained the English quality even when nasalized. The test contained twenty-four trials, each consisting of two pronunciations of each monosyllabic CVC word. The target words were three minimal pairs contrasting $/ \mathrm{m} /$ and $/ \mathrm{n} /$ in word-final position and preceded by a high (/I/), $\operatorname{mid}(/ \mathrm{E} /)$, or low (/Q /) vowel: Tim/tin, $\mathrm{gem} / \mathrm{gen}$ and $\mathrm{cam} / \mathrm{can}$. In this test each member of the three minimal pairs was repeated eight times.

The audio-stimuli were recorded by two speakers: one American native speaker of English proficient in BP, and one native speaker of BP proficient in English. Both speakers had phonetic training and could control their pronunciation so that the nasal was the only difference in the pronunciation of the target words; that is, the American English vowel quality was maintained during nasalization. The two speakers were recorded in individual sessions. Each word was recorded by each speaker twice with an English native-like pronunciation and twice with an intentionally Brazilian pronunciation. The best production of each word was selected by the non-native researcher and an assistant with phonetic training. The words were recorded in the program Sound Forge 7.0 and normalized for peak intensity.

Two types of trials were designed. The first type was a "different" trial that contained the two different pronunciations of the same word: one native-like pronunciation and one nonnative-like (e.g., $/ \mathrm{tlm} /-$ / 
tI . The second type was a "same" trial where there was no contrast; that is, both pronunciations of the target monosyllabic word were the same, either two native-like pronunciations or two nonnative-like pronunciations (e.g., either /tIm/-/tIm/ or $/ \mathrm{tl} / \mathrm{tl}$ ) ). The total of twenty-four trials consisted of twelve "different" trials and twelve "same" trials; thus, each of the six words appeared in two "different" trials and two "same" trials.

The words were sequenced in the program Praat 5.0. The material was digitally edited and the inter-trial interval set at $2.8 \mathrm{~s}$ and the interstimulus at $1.3 \mathrm{~s}$ following Flege (1994). The order of the trials was randomized to minimize any ordering effect. Each trial consisted of two items, and each of these spoken by a different speaker, as exemplified in one trial contrasting a N-like vs. a NN-like pronunciation of the English name Tim (with the high preceding vowel /I/):

\section{(Speaker 2) /tIm/ (Speaker 1) /tI)}

The participants received an answer grid for the test section with the written word, indicating what word was being pronounced. The written word was given because a small-scale pilot conducted by the first researcher with highly proficient speakers of English showed that the results of this identification test may be compromised if the participants are not aware of the word they are supposed to judge (Kluge, 2004). Participants had to indicate which pronunciation sounded more native-like in each trial by circling "1", "2"; "both", if they considered both pronunciations native-like; or "neither", if they considered neither pronunciation native-like.

A familiarization task of eight trials was also designed, consisting of four "different" trials and four "same" trials, but with other difficult pronunciation items instead of the nasals.

\subsection{Procedures}

The participants knew they were participating in a research project, but none of them was aware of the exact purpose of the study. Data was 
collected individually on a laptop computer. The oral instructions before all tests were given in Portuguese. First, the participants answered the questionnaire with their biographical information, and then they completed the tests in the following order: (1) the sentence reading test - 10-12 minutes, (2) break of 5 minutes, (3) Identification Test: nativelike vs. nonnative-like (10 minutes). Thus, the data collection for each participant lasted approximately 30 minutes.

\subsection{Analysis}

For the sentence reading test, 720 sentences ( 72 for each of the ten participants) were analyzed concerning the production or not of the nasal consonants $/ \mathrm{m} /$ and $/ \mathrm{n} /$ in word-final position, considering the preceding and following context. Of a total of 720 sentences, four sentences $(.55 \%)$ were excluded because the participants either misread or skipped the target word. The relevant parts of each sentence were segmented in Praat (version 4.5.14). Then, to determine the presence or absence of a fully realized English word-final nasal, each segmented part was analyzed by the first researcher both perceptually and through spectrograms.

The analysis of the results of the identification test was based on the total of 240 responses (24 for each of the ten participants) for the native-like vs. non-native productions, considering the "different" trials and the "same" trials.

Statistical tests were run using the SPSS software for Windows version 11.0. Skewness and kurtosis were checked to assess normal distribution, and even though some of the data seemed to be parametric, the tests used for analysis were non-parametric because of the small number of participants. Thus, the tests used to analyze the variables for production and perception were (a) Friedman, which is a nonparametric test equivalent to Repeated-measures ANOVA (Hatch \& Lazaraton, 1991), and (b) Wilcoxon tests, which were used for post hoc comparisons. The level of statistical significance (alpha level) was set at .05. 


\section{Results and discussion}

\subsection{Production}

The individual results of the production of the English nasal consonants $/ \mathrm{m} /$ and $/ \mathrm{n} /$ in word-final position by the ten Brazilian participants are shown in Table 1 , which indicates the number of correct productions - full realizations - for each of the target nasal consonants. There was considerable variability among the participants for the production of $/ \mathrm{m} /$, scores ranging from $44.44 \%$ to $94.44 \%$, with a mean of $63.87 \%$. Thus, on the whole, this nasal caused a considerable degree of difficulty. There was somewhat less variability for the production of $/ \mathrm{n} /$, scores ranging from $66.67 \%$ to $97.22 \%$, with a mean of $78.55 \%$, apparently indicating somewhat less difficulty as well.

\section{Table 1}

Individual results of the production test

\begin{tabular}{c|c|c|c|c}
\hline Participant & $\begin{array}{c}\text { No. Productions } \\
\text { /m/ }\end{array}$ & $\begin{array}{c}\text { No. Correct } \\
\text { Productions/m/ } /\end{array}$ & $\begin{array}{c}\text { No.Productions } \\
\text { /n/ }\end{array}$ & $\begin{array}{c}\text { No. Correct } \\
\text { Productions/n/ }\end{array}$ \\
\hline 1 & 36 & $34(94.44 \%)$ & 36 & $35(97.22 \%)$ \\
2 & 36 & $16(44.44 \%)$ & 36 & $30(83.33 \%)$ \\
3 & 36 & $33(91.67 \%)$ & 36 & $31(86.11 \%)$ \\
4 & 36 & $17(42.22 \%)$ & 36 & $26(72.22 \%)$ \\
5 & 36 & $22(61.11 \%)$ & 36 & $24(66.67 \%)$ \\
6 & 35 & $27(77.14 \%)$ & 35 & $28(80.00 \%)$ \\
7 & 34 & $24(70.59 \%)$ & 36 & $28(77.78 \%)$ \\
8 & 36 & $22(61.11 \%)$ & 36 & $24(66.67 \%)$ \\
9 & 36 & $17(42.22 \%)$ & 36 & $26(72.22 \%)$ \\
10 & 36 & $16(44.44 \%)$ & 36 & $30(83.33 \%)$ \\
\hline Total & 357 & $228(63.87 \%)$ & 359 & $282(78.55 \%)$ \\
\hline
\end{tabular}

A Wilcoxon test was run in order to verify whether the difference between the production of $/ \mathrm{m} /$ and $/ \mathrm{n} /$ was significant. The test yielded a significant result $(\mathrm{Z}=-.2 .406, \mathrm{p}=.016)$, confirming that the production 
of the nasal $/ \mathrm{m} /$ in word-final position was more difficult for the Brazilian learners than the production of the nasal $/ \mathrm{n} /$ in the same position, and corroborating the results of Kluge (2004) and Kluge et al. (2007).

Word-final nasals in BP are almost always written with the grapheme 'm' (e.g., fim - 'end', correm - 'they run'), with only a few exceptional words written with 'n' (e.g., hífen - 'hyphen', pólen 'pollen'). Thus, the results suggest that when the English words ended in ' $\mathrm{m}$ ', association was more often made with the L1 phonological processes, causing the vowel nasalization/consonant deletion error. Words ending in ' $n$ ', causing a less frequent association with the L1, resulted in less frequent transfer of the L1 process.

Regarding the strategies used by the Brazilian learners when they did not fully pronounce the English final nasal consonant / m/ (129 out of 357 cases) or $/ \mathrm{n} /$ (77 out of 359 cases), the spectrographic analysis in Praat shows that the participants nasalized the preceding vowel and deleted the following nasal consonant in all cases for both nasal consonants. That is, vowel nasalization and nasal consonant deletion was the only strategy used by the Brazilian participants, which corroborates the results of Monahan (2001), Baptista and Silva Filho (1997), Kluge (2004), and Kluge et al. (2007), and supports Hypothesis 1. As to the second research question, Table 2 shows the results of the production of the English wordfinal nasals $/ \mathrm{m} /$ and $/ \mathrm{n} /$ according to the preceding vowel, which was either /I / (high), /E/ (medium) or /Q / (low).

\section{Table 2}

Results of the production of English word-final nasals / $\mathrm{m} /$ and / $\mathrm{n} /$ by preceding vowel

\begin{tabular}{l|c|c|c|c}
\hline $\begin{array}{l}\text { Preceding } \\
\text { vowel }\end{array}$ & $\begin{array}{c}\text { Productions } \\
\text { /m/ }\end{array}$ & $\begin{array}{c}\text { Correct Productions } \\
\text { /m/ }\end{array}$ & $\begin{array}{c}\text { Productions } \\
\text { /n/ }\end{array}$ & $\begin{array}{c}\text { Correct } \\
\text { Productions /n/ }\end{array}$ \\
\hline /I/ & 120 & $60(50.00 \%)$ & 119 & $97(81.51 \%)$ \\
/E/ & 118 & $90(76.27 \%)$ & 120 & $92(76.67 \%)$ \\
/Q/ & 119 & $78(65.55 \%)$ & 120 & $93(77.50 \%)$ \\
\hline Total & 357 & $228(63.87 \%)$ & 359 & $282(78.55 \%)$ \\
\hline
\end{tabular}


The results displayed in Table 2 seem to indicate that the vowel after which the participants had the most difficulty in producing the English word-final nasal / $\mathrm{m} /$ was the high vowel / / and that the mid vowel /E/ seemed to favor the full realization of the English nasal consonant $/ \mathrm{m} /$. However, the Friedman statistical test showed a nonsignificant effect for preceding vowel followed by $/ \mathrm{m} /\left(X^{2}(2, N=10)=\right.$ $5.200, p=0.074)$. These results may be due to insufficient data for a more conclusive statistical analysis, and to the fact that two participants reached near ceiling results.

The results for word-final $/ \mathrm{n} /$ do not show great variation in the context of all the three preceding vowels investigated. Thus, the Friedman statistical test for the production of the alveolar nasals yielded a nonsignificant effect for preceding vowel $\left(X^{2}(2, N=10)=0.320, p=0.852\right)$.

Despite the non-significant results for both target nasals, results are not in the direction hypothesized in this study. Our hypothesis predicted that low preceding vowels would disfavor the complete realization of the English word-final nasals (Krakow, 1995; Kluge, 2004; Kluge et al., 2007), which was definitely not the case here. Actually, in the present study, results are inconsistent: for $/ \mathrm{m} /$, the best performance was in the context of the preceding mid vowel; while for $/ \mathrm{n} /$, the best performance was in the context of the preceding high vowel. The poorest performance for $/ \mathrm{m} /$ was in the context of the preceding high vowel, and for $/ \mathrm{n} /$ it was in the context of the preceding mid vowel. So, it is unclear whether preceding vowel plays much of a role in the production of $/ \mathrm{m} /$ and $/ \mathrm{n} /$ or whether there are other more important variables responsible for the results of this study.

\subsection{Perception}

The third research question aimed at investigating whether the Brazilian EFL learners would be able to perceive the distinction between a native-like vs. nonnative-like realization of English word-final nasals $/ \mathrm{m} /$ and $/ \mathrm{n} /$, differing in the presence or absence of fully-realized English word-final nasals and in the nasalization (or not) of the previous vowel, and identify the native-like one. Table 3 shows the responses of 
the participants for each of the four expected (appropriate) responses ("1", "2", "both" or "neither"). As explained in 4.2.2, in "different" trials, the native-like pronunciation appeared in one of the two positions " 1 " or " 2 ", whereas in the "same" trials there was no different pronunciation, and the correct answer would be either "both" (were native-like) or "neither" (was native-like).

The number of responses in Table 3 was based on a total of 6 responses ( 3 for each nasal) for the pronunciation of the nasals in each of the four possible responses (" 1 ", "2", "both" or "neither") for each of the 10 participants, resulting in a total of 60 responses per position. The correct responses and percentages for each of the four response types are in bold. As there were too few tokens for a separate analysis of each of the word-final nasal consonants, the results were analyzed combining both nasal consonants $/ \mathrm{m} /$ and $/ \mathrm{n} /$.

\section{Table 3}

Participants' responses in the identification of native-like vs. nonnativelike nasals.

\begin{tabular}{l|c|c|c|c}
\hline Expected & \multicolumn{4}{|c}{ Participant Responses } \\
\cline { 2 - 5 } Response & "1" & "2" & "Both" & "Neither" \\
\hline "1" & $51(\mathbf{8 5 . 0 0 \% )}$ & 4 & 1 & 4 \\
"" & 7 & $\mathbf{4 6}(\mathbf{7 6 . 6 7 \% )}$ & 7 & - \\
"Both" & 20 & 15 & $\mathbf{2 5}(\mathbf{4 1 . 6 7 \% )}$ & - \\
"Neither" & 15 & 12 & 5 & $\mathbf{2 8 ~ ( 4 6 . 6 7 \% )}$ \\
\hline
\end{tabular}

Note: $n=60$ for each expected response; correct participant responses in bold.

Table 3 shows that the total percentages of correct answers were much higher in the "different" trials, when the correct response was either " 1 " $(85 \%)$ or " 2 " $(76.67 \%)$, than in the "same" trials, when the correct response was either "both" (41.67\%) or "neither" (46.67\%). The Friedman statistical test showed a significant effect for type of expected response in the discrimination and identification of native-like 
pronunciation of word-final $/ \mathrm{m} /$ and $/ \mathrm{n} /\left(\mathrm{X}^{2}(3, \mathrm{~N}=10)=18.256, \mathrm{p}=\right.$ .000). Therefore, Wilcoxon tests were run in order to verify which pairs of expected response were significant. The test results showed that for only two pairs the difference was not significant: " 1 " versus " 2 " ( $Z=$ $1.633, \mathrm{p}=.102)$, and "neither" versus "both" $(\mathrm{Z}=-.425, \mathrm{p}=.671)$. The test results for all four other pairs showed that the difference was significant, as follows: (a)"1" versus "both" $(Z=-2.728, p=.006)$; (b) "1" versus "neither" $(Z=-2.555, p=.011)$; (c) " 2 " versus "both" $(Z=-2.080, p=$ $.038)$; and $(\mathrm{d})$ " 2 " versus "neither" $(\mathrm{Z}=-2.414, \mathrm{p}=.016)$.

The lack of significant difference between " 1 " and " 2 " shows that there was no position effect, thus validating the results of this study. Also, the fact that both " 1 " and " 2 " scored higher than "both" and than "neither" indicates that it was easier to identify the native-like pronunciation of the word-final nasal when there was a contrast, that is, when they heard both, than when there was no contrast. In other words, when the two pronunciations were the same, they were not sure if they were both native-like or both nonnative-like, supporting Hypothesis 3. However, Table 3 also shows that when the participants heard either two native-like or two nonnative-like pronunciations, they either responded correctly or responded " 1 " or " 2 "; they never responded "neither" when it was "both", and there were only 5 responses for "both" when it was "neither". This, unfortunately, indicates that they expected the trials to be "different" trials and guessed at which one was native-like.

\section{Conclusion}

This research was an investigation of the perception and production of English nasal consonants $/ \mathrm{m} /$ and $/ \mathrm{n} /$ in word-final position by a group of ten intermediate Brazilian learners of English. The production results of this study support the first hypothesis, which stated that when the Brazilian learners of English did not fully realize the English wordfinal nasal consonant, they would also nasalize the preceding vowel.

The results also show that the nasal consonant $/ \mathrm{n} /$ was more accurately produced than $/ \mathrm{m} /$ in word-final position. This suggests 
that the participants associated the English words ending in " $\mathrm{m}$ " with the vowel nasalization/consonant deletion process in BP, as most wordfinal nasals in BP are written with the grapheme " $\mathrm{m}$ ". English words ending in " $n$ " seemed to cause less association with BP.

The second hypothesis, however, which predicted that the height of the preceding vowel would influence the Brazilian EFL learners' production of English word-final nasals, was not supported. Statistical analyses showed no significant results for preceding vowel followed by either $/ \mathrm{m} /$ or $/ \mathrm{n} /$. The second part of the hypothesis, which specified that low preceding vowels would disfavor the complete realization of the nasal consonant, was not supported either. In fact, non-significant results indicate a slight tendency for preceding high vowels to disfavor the accurate production of the nasal consonant $/ \mathrm{m} /$. The non-significant results may be due to the limited number of subjects and tokens analyzed and due to the ceiling effect, but would have to be verified in a study with more participants.

Regarding perception, the third hypothesis stated that the Brazilian learners would be able to perceive the distinction between a nativelike versus nonnative-like pronunciation of English word-final nasals and identify the native-like one only when there was a contrast. The first part of the hypothesis was supported, as the participants did score better in perception in the "different" trials, where they were able to identify the native-like realization of English word-final nasals 85\% and $76 \%$ of the time, than in the "same" trials, where there was no contrast. However, it was also shown that when the participants heard either two-native-like or two-nonnative-like realizations of the same English word, they expected there would be a difference, guessing that either the first or the second realization was native-like.

This apparent guessing, on the one hand, may limit the validity of the test itself, suggesting that the participants were more concerned with "getting it right" than with giving honest answers. However, the much better-than-chance results of the " 1 " and " 2 " responses suggest another explanation. They suggest that, while the participants have good enough perception to identify the English versus the Portuguese- 
sounding phonetic sequences when in contrast, they have not yet actually formed a phonetic category for these "position-sensitive allophones" (Flege, 1995), which would allow them to be sure when two phonetic sequences are the same. In addition to the association caused by spelling, the fact that BP syllable-final nasals are generally realized, even if minimally, when immediately followed by a homorganic oral stop, would cause the Brazilian learner of English to perceive a similarity between the nasals of the two languages and make an association between them, making the formation of the L2 category more difficult than for a totally unfamiliar L2 sound (Flege, 1995).

During the process of data analysis, some limitations of this study became apparent. The limited number of subjects and tokens to be analyzed for production and perception made it difficult to achieve statistically significant results. Another important limitation is the lack of a group of native speakers of English to take the perception test as a reference for comparison, especially since previous studies have shown the perception of syllable-final nasals to be difficult even for native English speakers.

In terms of variables, the present study did not investigate the following context for production or the possible effect of preceding vowel in the native-like vs. nonnative-like Identification test.

The limitations found in this study, however, lead to suggestions for future research, such as: (1) the investigation of following phonological context: vowels, silence, consonants and their place of articulation; (2) a further investigation of the production of word-final (and syllable-final) nasal consonants by Brazilian learners examining the degree of realization of the English word-final nasal; and (3) the investigation of whether there is a correlation between the production and perception of the English word-final nasal.

Theoretical implications of the results of this study were suggested above in regard to Flege's Speech Learning Model. In spite of the tentative nature of the results of this study, two important pedagogical implications can be suggested as well: (1) While the perception of the place of articulation of final nasal consonants may be inherently difficult, the articulation of these sounds should not be so difficult for speakers 
whose native language permits the nasal consonants in two other positions (e.g., word-initial and word-medial in PB, although in the latter it may be incompletely realized). The problem appears to be the association with the PB phones, causing learners to automatically carry out the normal PB phonological processes. Possibly perception training from the beginning of English study, even if it does not reach the point of perfecting the perception itself, will help to raise awareness of the differences between the two languages, reducing the association and, thus, reducing the tendency to carry out the PB phonological processes of vowel nasalization and nasal consonant deletion. (2) The greater difficulty found in this study for the final $/ \mathrm{m}$ / compared to the final $/ \mathrm{n} /$ should indicate that this is where the emphasis in pronunciation should be given.

Authors's Note: The first author would like to thank the Committee for Postgraduate Courses in Higher Education (CAPES) for funding the present research.

\section{References}

Aoyama, K. (2003). Perception of syllable-initial and syllable-final nasals in English by Korean and Japanese speakers. Second Language Research, 19, 251-265.

Baptista, B. O., \& Silva Filho (2006). The influence of voicing and sonority relationship on the production of English final consonants. In B. O. Baptista \& M. A. Watkins (Eds.) English with a Latin beat: Studies in Portuguese/Spanish-English Interphonology (pp.73-90). Amsterdam: John Benjamins.

Câmara Jr., J.M. (1971). Problemas da lingüística descritiva. Petrópolis: Vozes.

Carlisle, R. S. (1994). Markedness and environment as internal constraints on the variability of interlanguage phonology. In M. Yavas (Ed.), First and second language phonology (pp.223-250). San Diego: Singular.

Cristófaro Silva, T. (1999). Fonética e fonologia do português: Roteiro de estudos e guia de exercícios. São Paulo: Contexto.

Eckman, F. R. (1977). Markedness and the contrastive analysis hypothesis. Language Learning, 27, 315-330. 
Flege, J. E. (1981). The phonological basis of foreign accent: a hypothesis. TESOL Quarterly, 15, 443-455.

Flege, J. E. (1995). Second language speech learning: theory, findings, and problems. In Strange, W. (Eds.), Speech perception and linguistic experience: Issues in crosslanguage research (pp. 233-277). Timonium, MD: York.

Flege, J. E., \& Davidian, R. D. (1984). Transfer and developmental processes in adult foreign language speech production. Applied Psycholinguistics, 5, 323-347.

Flege, J. E., Munro, M. J., \& Fox, R. A. (1994). Auditory and categorical effects on cross-language vowel perception. Journal of the Acoustical Society of America, 95, 3623-3641.

Fujimura, O. (1962) Analysis of Nasal Consonants. Journal of the Acoustical Society of America, 34, 1865-1875.

Fujimura, O., \& Erickson, D. (1997). Accoustic Phonetics. In. W.J. Hardcastle \& J. Laver (Eds), The handbook of phonetic sciences. Cambridge: Blackwell.

Giegerich, H. J. (1992). English phonology: An introduction. Cambridge: Cambridge Univesity Press.

Harnsberger, J.D. (2000). A cross-language study of the identification of non-native nasal consonants varying in place of articulation. Journal of the Acoustical Society of America, 108, 764-783.

Harnsberger, J.D. (2001). The perception of Malayalam nasal consonants by Marathi, Punjabi, Tamil, Oriya, Bengali, and American English listeners: A multidimensional scaling analysis. Journal of Phonetics, 29, 303-327.

Hatch, E., \& Lazaraton, A. (1991). The research manual: Design and statistics for applied linguistics. New York: Newburry.

Kluge, D. C. (2004). The perception and production of English syllable-final nasals by Brazilian learners. Unpublished master's thesis. Florianópolis: Universidade Federal de Santa Catarina.

Kluge, D. C., Rauber, A. S., Reis, M. S., Bion, R.A.H. (2007). The relationship between perception and production of English nasal codas by Brazilian learners of English. In Proceedings of Interspeech 2007 (pp. 2297-2300). Antwerp. 
Krakow, R. A. (1995). Nonsegmental influences on velum movement patterns: syllables, sentences, stress and speaking rate. In: M. K. Huffman \& R.A. Krakow (Eds.) Nasals, Nasalization and the Velum (pp. 87-116). San Diego: Academic Press.

Kurowski, K. M., \& Blumstein, S. E. (1984). Perceptual integration of the murmur and formant transition for place of articulation in nasal consonants. Journal of the Acoustical Society of America, 76, 383-390

Kurowski, K. M., \& Blumstein, S. E. (1987). Acoustic properties for place of articulation in nasal consonants. Journal of the Acoustical Society of America, 81, 1917-1927

Kurowski, K. M., \& Blumstein, S. E. (1995). Acoustic properties for the perception of nasal consonants. In M. K. Huffman \& R.A. Krakow (Eds.), Nasals, Nasalization and the Velum (pp. 197-222). Academic Press.

Major, R. C. (1994). Current trends in interlanguage phonology. In M. Yavas (Ed.), First and second language phonology (pp. 181-204). San Diego: Singular.

Mateus, M. H. M., \& d'Andrade, E. (2000). The phonology of Portuguese. Oxford: Oxford University Press.

Monahan, P. J. (2001). Evidence of transference and emergence in the interlanguage (DOC 444-0701). Rutgerss Center of Cognitive Science. Available: http:// roa.rutgers.edu [2001, December 3].

O'Connor, J. D. (1975). Better English pronunciation. Cambridge: Cambridge University Press.

Ohde, R. N., Haley, K. L., Barnes, C. W. (2006). Perception of the [m]-[n] distinction in consonant-vowel (CV) and vowel-consonant (VC) syllables produced by child and adult talkers. Journal of the Acoustical Society of America, 119, 1697-1711.

Repp, B. (1986). Perception of the [m]-[n] distinction in CV syllables. Journal of the Acoustical Society of America, 79, 1987-1999.

Repp, B., \& Svastikula, K. (1988). Perception of the [m]-[n] distinction in VC syllables. Journal of the Acoustical Society of America, 83, 237-247. 